$11-1-2019$

\title{
Behavior prioritization to improve SBC (Social and Behavior Change) programming during a public health emergency: A call to action
}

Breakthrough RESEARCH

Follow this and additional works at: https://knowledgecommons.popcouncil.org/departments_sbsr-pgy

Part of the Health Communication Commons, and the Public Health Commons

How does access to this work benefit you? Let us know!

\section{Recommended Citation}

Breakthrough RESEARCH. 2019. "Behavior prioritization to improve SBC (Social and Behavior Change) programming during a public health emergency: A call to action," Programmatic Research Brief. Washington, DC: Population Council. 


\title{
Behavior prioritization to improve SBC programming during a public health emergency: a call to action
}

\begin{abstract}
As the international development community continues to manage public health challenges and emerging diseases, the need for behavior prioritization is critical. The information outlined within the brief is intended to provide the rationale for why behavior prioritization is instrumental to improve social and behavior change (SBC) programming and ends with a call to action for different stakeholders to advocate for and engage in behavior prioritization processes as part of SBC program design, planning, and adaptation.
\end{abstract}

\section{KEY POINTS}

- A key step of SBC programming is to identify and prioritize key behaviors and target audiences to increase the potential for impact and achieve desired behavioral and health outcomes.

- Promoting too many behaviors has the potential to lead to ineffective or even counterproductive outcomes, as individuals who are asked to perform too many behaviors, may be less likely to change any behavior.
During the Zika outbreak in Latin America, a review of USAID-supported programming in 2017 showed that more than 30 Zika preventive behaviors and messages were being promoted by different implementing partners within and across countries. ${ }^{1}$ The messaging around desired behaviors was also often general, such as "keep your patio clean", instead of specific, such as "remove sources of standing water from your patio". This created confusion in target populations and a lack of consistency in messaging and materials among partners. Research shows that individuals who are asked to perform too many behaviors, may be less likely to change any behavior, ${ }^{2}$ as they may experience difficulty choosing which behavior to adopt, a phenomenon known as choice conflict. ${ }^{3}$ Furthermore, when presented with vague messages, such as "clean your patio", the desired behaviors are up to the interpretation of the individual, who may choose, for example, to sweep, or remove trash, instead of the desired behavior of removing standing water. Best practices from behavioral science, social marketing, human-centered design, and other areas of research have shown that promoting clear messages from a short list of behaviors clearly, concisely, consistently and with specificity improves behavioral uptake. ${ }^{4}$

Through an evidence-based and consultative process, USAID and a team of implementing partners with varied technical expertise (entomological, clinical, SBC) in the USAID Zika response prioritized seven key prevention behaviors within three broad categories (personal protection, household and community vector control, and prevention-enabling behaviors). ${ }^{1}$ Criteria used to evaluate the behaviors included: evidence of effectiveness in preventing transmission of arboviruses or reducing the vector population, attributes such as frequency of performance of the behavior required to be effective; feasibility of the behavior (single vs multiple steps or negotiating with others); and availability and accessibility of required materials (see Box 1). The seven prioritized behaviors validated among implementing partners in the Zika response are:

1. Using mosquito repellent.

2. Using condoms to prevent sexual transmission.

3. Regularly removing unintentional standing water both inside and outside the house.

4. Covering water storage containers at all times with a tight-fitting cover that does not warp or touch the water.

5. Eliminating mosquito eggs from walls of water storage containers weekly.

6. Seeking prenatal care.

7. Seeking family planning counseling if not planning a pregnancy.

Stakeholders in the Zika response identified the behavior prioritization process and ensuing adaptation of SBC programming as extremely successful in focusing efforts. ${ }^{6}$

\section{BOX 1 ATTRIBUTES OF THE BEHAVIOR}

Attributes of the behavior-such as its feasibility, whether it needs to be repeated, the skill level required, its tangible and opportunity costs, and its dependency on others-can influence whether a person will adopt or modify an existing behavior. 


\section{Call to action}

During a public health emergency, evidence-based behavior prioritization is a necessary step for achieving desired behavioral and health outcomes. As a best practice, stakeholders within the behavioral and clinical/epidemiological sciences, program implementing partners, and government and community stakeholders should come together to agree upon a prioritized, evidence-based, practical, and feasible set of behaviors for targeted populations.

Table 1 presents key stakeholders and actions for advocating and utilizing behavior prioritization as a key step in SBC programming.

\section{TABLE 1 CALL TO ACTION}

\begin{tabular}{|ll|}
\hline DONORS & - Include and advocate for behavior prioritization as an integral part of program design among \\
implementing partners. & - Facilitate prioritization process to ensure coordination and alignment of SBC strategies and \\
approaches between partners. & - Use behavior prioritization evidence to influence and update key strategies and policies as \\
GOVERNMENT \& & appropriate. \\
POLICYMAKERS & - Advocate for behavior prioritization as a key element for SBC design and planning in a \\
SBC PRACTITIONERS & - Review sources of evidence as part of the prioritization process. \\
& - Document implementation experiences and success stories on the effect of behavior prioriti- \\
& - Mation as a key SBC strategy. \\
& - Participate in behavior prioritization processes to provide technical expertise where evidence \\
OTHER PUBLIC HEALTH & is inconclusive or insufficient. \\
AND DEVELOPMENT & - Find, synthesize, and share evidence to help inform the behavior prioritization process. \\
PRACTITIONERS & - Participate in the behavior prioritization process to assist in interpretation of the evidence. \\
RESEARCHER & Evaluate programmatic impact of behavior prioritization. \\
INSTITUTIONS \& &
\end{tabular}

\section{References}

${ }^{1}$ Pinchoff, J. et al. 2019. "Evidence-based process for prioritizing behavior-change messages: Zika prevention in Latin America and the Caribbean and applicability to future health emergency responses," Global Health: Science and Practice 7(3):404-417; https://doi.org/10.9745/GHSP-D-19-00188

${ }^{2}$ McDonald, J. et al. 2017. "Recalling and intending to enact health recommendations: optimal number of prescribed behaviors in multibehavior messages," Clinical Psychological Science 5(5): 858-865.

${ }^{3}$ Tversky, A. and E. Shafir. 1992. "Choice under conflict: the dynamics of deferred decision," Psychological Science 3: 358-361.

${ }^{4}$ Piotrow, P. T. et al. 1997. Health Communication: lessons from family planning and reproductive health. Westport, CT: Praeger.

${ }^{5}$ Silva, M. et al. 2019. "Lessons learned from the SBC programming in the USAID Zika response," Technical Report. Washington DC: Population Council, Breakthrough RESEARCH.

${ }^{6}$ Edmeades, J. \& S. Mathur. 2019. "Insights to improve social and behavior change programming through a focus on the attributes of behaviors," Research Brief. Washington DC: Population Council, Breakthrough RESEARCH.

\section{Breakthrough RESEARCH}

Our project turns evidence into action by providing thought provoking guidance to improve SBC policy and programming, with the goal of improving the costeffectiveness of USAID's health and development strategies. Breakthrough RESEARCH catalyzes SBC by conducting state-of-the-art research and evaluation and promoting evidence-based solutions to improve health and development programs around the world.

Breakthrough RESEARCH is made possible by the generous support of the American people through the United States Agency for International Development (USAID) under the terms of cooperative agreement no. AID-0AA-A-17-00018. The contents of this document are the sole responsibility of the Breakthrough RESEARCH and Population Council and do not necessarily reflect the views of USAID or the United States Government.

Population Council

4301 Connecticut Avenue, NW | Suite 280 | Washington, DC 20008

Tel: +1 2022379400 | breakthroughresearch@popcouncil.org

breakthroughactionandresearch.org

Suggested citation: Breakthrough RESEARCH. 2019. "Behavior prioritization to improve SBC programming during a public health emergency: a call to action," Programmatic Research Brief. Washington DC: Population Council. 